\title{
Maintaining thermal stability of a fill slope in cryolithozone
}

\author{
Elena Romanova ${ }^{1 *}$ and Yuri Khokholov ${ }^{1}$ \\ ${ }^{1}$ Mining Institute of the North, Siberian Branch, Russian Academy of Sciences, 677980, Russian Fed- \\ eration, Sakha Republic (Yakutia), Yakutsk, pr. Lenina, 43.
}

\begin{abstract}
The paper describes a solution to the problem of maintain the stability of a fill slope through artificial freezing with seasonal cooling units in cryolithozone. A three-dimensional mathematical model was developed to calculate the heat flow in a fill slope reinfirced with a gabion wall, taking into account the liquid-liquid phase transition and the use of seasonally operating cooling units. The developed mathematical model, based on the finite difference method and implemented as an application for Microsoft Windows, allows making a long-term forecast of a temperature field in a fill slope, depending on various design and technological parameters (location, dimensions and an operating mode of thermal stabilizers) and its effect on the stability of the slope. The results of studying the contribution of thermal stabilization to a reduced destructive temperature effect of the environment on the slope are given. The study showed the effectiveness of using seasonal cooling units for increasing the stability of fill slopes by freezing. In subsequent years after the thermal stabilization, the frozen zone in the fill slope is preserved, with the slope gradually switching to the natural seasonal temperature regime. The paper is recommended for researchers and designing engineers dealing with applied issues of mining thermal physics.
\end{abstract}

Keywords: slope, cryolithozone, thermal stabilization, thermal regime, mathematical model, stability, seasonal cooling unit.

\section{Introduction}

Prone to landslides and ground displacement, slopes pose a danger to human life. Artificial freezing of soils is one of universal and reliable ways to stabilize them and ensure their waterproofness. This paper solves the problem of ensuring the stability of a fill soil slope by artificial freezing with seasonal cooling units (SCU) in cryolithozone. An important feature of the SCUs is that they do not require external power supply and operate using the natural cold of the atmospheric air. The SCUs help to solve complex technical problems during construction on permafrost and significantly reduce expenditures. However, the use of these units requires scientific justification, calculations, and experience. Over time, if used without a reason, instead of a positive effect on permafrost ground massifs (increased bearing capacity), they may have a negative effect (frost cracking, soil swelling, etc.) [1].

\footnotetext{
*Corresponding authors: helconst@mail.ru
} 


\section{Mathematical model}

The considered slope is a fill soil one made on a natural slope and reinforced with a gabion wall to protect the motor way. To maintain the stability of the slope with frozen ground, there were installed vertical SCU thermal stabilizers operating in the cold season in two staggered rows along the wall and in one row on the top of the slope.

The heat transfer in the ground is described using the non-stationary thermal conductivity equation taking into account the liquid-liquid phase transitions:

$$
C_{e f f}(T) \cdot \frac{\partial T}{\partial t}=\frac{\partial}{\partial x}\left(\lambda(T) \cdot \frac{\partial T}{\partial x}\right)+\frac{\partial}{\partial y}\left(\lambda(T) \cdot \frac{\partial T}{\partial y}\right)+\frac{\partial}{\partial z}\left(\lambda(T) \cdot \frac{\partial T}{\partial z}\right)+q(x, y, z, t),
$$

where $C_{\text {eff }}$ is the effective heat capacity, $\mathrm{J} /\left(\mathrm{m}^{3} \cdot \mathrm{K}\right) ; \lambda$ is the thermal conductivity coefficient of the ground, $\mathrm{W} /(\mathrm{m} \cdot \mathrm{K}) ; q$ is the intensity of internal heat sources, $\mathrm{W} / \mathrm{m}^{3}$.

To take the phase transition heat into account, one first needs to calculate the effective heat capacity:

$$
C_{e f f}(T)=C(T)+\sum_{\mu=1}^{\mu_{0}} L_{p h} \cdot W \cdot \rho \cdot \delta_{\mu}\left(T-T^{*}\right),
$$

where $C$ is the volumetric heat capacity of the ground, $\mathrm{J} /\left(\mathrm{m}^{3} \cdot \mathrm{K}\right) ; L_{p h}$ is the liquid-liquid phase transition heat, $\mathrm{J} / \mathrm{kg} ; W$ is the ground moisture, unit fractions; $\rho$ is the ground density, $\mathrm{kg} / \mathrm{m}^{3}$; $T^{*}$ is the water melting (freezing) temperature in the ground, $\mathrm{C}^{\circ} ; \delta$ is the Dirac function; $\mu$ is the number of the phase transition front $\left(\mu=1, \ldots, \mu_{0}\right)$.

The heat capacity and thermal conductivity coefficients are discontinuous and are as follows:

$$
C(T)=\left\{\begin{array}{l}
\rho_{\text {sld.mtx }} \cdot\left(c_{\text {sld.mtx }}+c_{\text {ice }} \cdot W\right), \quad T<T^{*}, \\
\rho_{\text {sld.mtx }} \cdot\left(c_{\text {sld.mtx }}+c_{\text {water }} \cdot W\right), \quad T>T^{*},
\end{array} \quad \lambda(T)= \begin{cases}\lambda_{f}, & T<T^{*}, \\
\lambda_{t h}, & T>T^{*},\end{cases}\right.
$$

where $c_{\text {sld.mtx }}$ is the solid matrix specific heat capacity $(\mathrm{J} /(\mathrm{kg} \cdot \mathrm{K})) ; \rho_{\text {sld.mtx }}$ is the solid matrix density $\left(\mathrm{kg} / \mathrm{m}^{3}\right) ; c_{i c e}, c_{\text {water }}$ are the specific heat capacities of the ice and water, respectively $(\mathrm{J} /(\mathrm{kg} \cdot \mathrm{K})) ; \lambda_{f}, \lambda_{t h}$ are the thermal conductivity coefficients $(\mathrm{W} /(\mathrm{m} \cdot \mathrm{K}))$ for frozen (thawed) grounds, respectively.

On the day surface, $B_{\text {surf }}$ is the Newton's boundary condition, modelling the convective heat exchange between the solid body surface and the atmospheric air:

$$
\lambda \cdot \frac{\partial T}{\partial n_{B_{\text {surf }}}}=\alpha_{\text {surf }} \cdot\left(T-T_{\text {atm.air }}\right), \quad(x, y, z) \in B_{\text {surf }},
$$

where $\partial / \partial n_{\text {surf }}$ is the outward normal to the boundary $B_{\text {surf; }} \alpha_{\text {surf }}$ is the coefficient of heat transfer through the day surface, $\mathrm{W} /\left(\mathrm{m}^{2} \cdot \mathrm{K}\right) ; T_{\text {atm.air }}$ is the atmospheric air temperature, ${ }^{\circ} \mathrm{C}$.

On the thermal effect boundaries $B$ th eff, there is the Newmann's boundary condition:

$$
\lambda \cdot \frac{\partial T}{\partial n_{B_{\text {th.eff }}}}=0, \quad(x, y, z) \in B_{\text {th.eff }},
$$

where $\partial / \partial n_{\text {Bth.eff }}$ is the outward normal to the boundary $B_{\text {th.eff. }}$

For the initial time, the initial ground temperature distribution is calculated:

$$
T(x . y, z, 0)=T^{0}(x \cdot y, z) \text {. }
$$

The developed mathematical model was made with a numerical method, namely by the finite-difference method [2,3], and implemented as an application for Microsoft Windows. The program allows assessing the effect of various design and technological parameters (location, dimensions and an operating mode of thermal stabilizers) on the fill slope stability. 


\section{Temperature regime forecast for the fill slope without thermal stabilization}

Calculations were made taking into account the climatic and engineering-geological conditions of the location of a fill slope in Magadan region. The climatic conditions data (mean daily air temperatures, average monthly wind speeds and snow thicknesses) were taken from reference materials on the Magadan region climate. Thermal physical characteristics of the soils and the material filling the gabions were taken from the data obtained during engineering and geological surveys.

The fill slope, reinforced with a retaining wall, was made in mid-September. Initially, the fill soil had a positive temperature equal to the atmospheric one.

The calculations showed that in the first year after the fill slope is made, an extensive thawed zone forms in it; by the onset of the warm season (early May) it occupies $65 \%$ of the fill slope soils volume, and by the onset of the cold season, the merging with the seasonally thawed soil is $98 \%$ (late September). Figure (1) shows the temperature distribution in the slope in year 1 of operation (late September). Every year, the thawed zone gradually decreases: in year 2, it makes $59 \%$ in spring and $87 \%$ in autumn; in year $3-52 \%$ in spring and $78 \%$ in autumn; in year $4-45 \%$ in spring and $70 \%$ in autumn. Only in year 5 , the thawed zone in the slope gets surrounded by frozen ground and stops merging with the seasonally thawed soil, making up $38 \%$ of the fill slope volume in spring. The thawed zone in the fill slope continues to decline, in year 8 it makes $48 \%$ in spring, and finally disappears in the winter of year 11 (see Figure 2).

Thus, if the hydrogological regime of surface waters is disturbed, a talik formed in a fill slope in the first four years after making can result in the formation of zones with high water content. The talik remaining inside the embankment continues to be a source of slope instability and deformation.

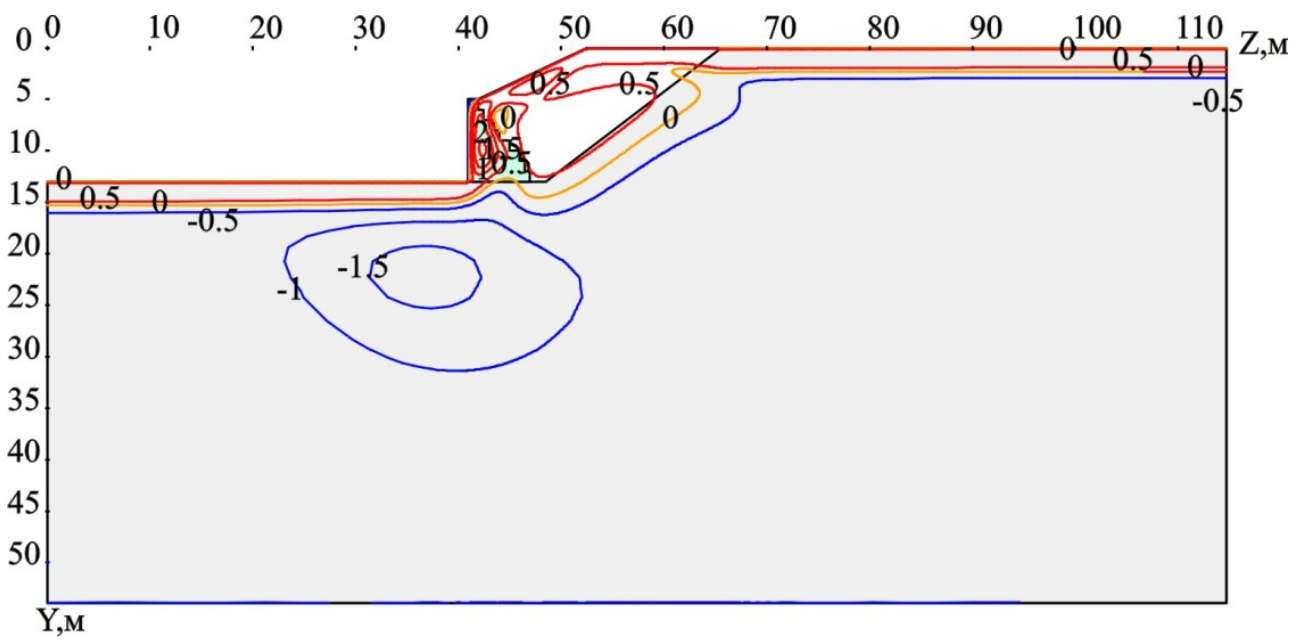

Fig.1. Temperature $\left({ }^{\circ} \mathrm{C}\right)$ distribution in the ground with no thermal stabilizers (late September, year 1 of operation) 


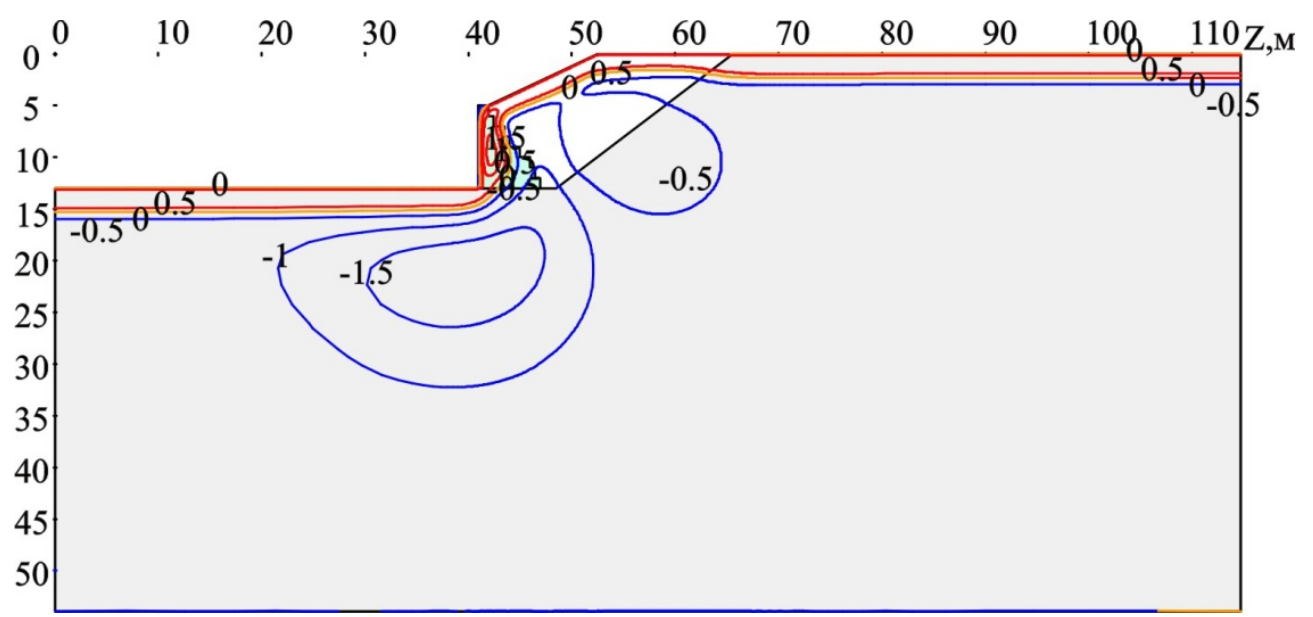

Fig.2. Temperature $\left({ }^{\circ} \mathrm{C}\right)$ distribution in the ground with no thermal stabilizers (late September, year 11 of operation)

\section{The effect of thermal stabilizers on thermal regime of the fill slope}

In order to increase the bearing capacity of the ground, after the construction of the fill slope, it is frozen with thermal stabilizers. Thermal stabilizers turn on when the ambient air temperature drops below $-10^{\circ} \mathrm{C}$. During their operation, the thermal stabilizers maintain the temperature $5^{\circ} \mathrm{C}$ higher than the atmospheric air temperature, which does not fall below $10^{\circ} \mathrm{C}$.

The calculations showed that the thawed zone in the fill slope gradually decreases and disappears completely after the thermal stabilizers operate for four years (see Figures 3, 4).

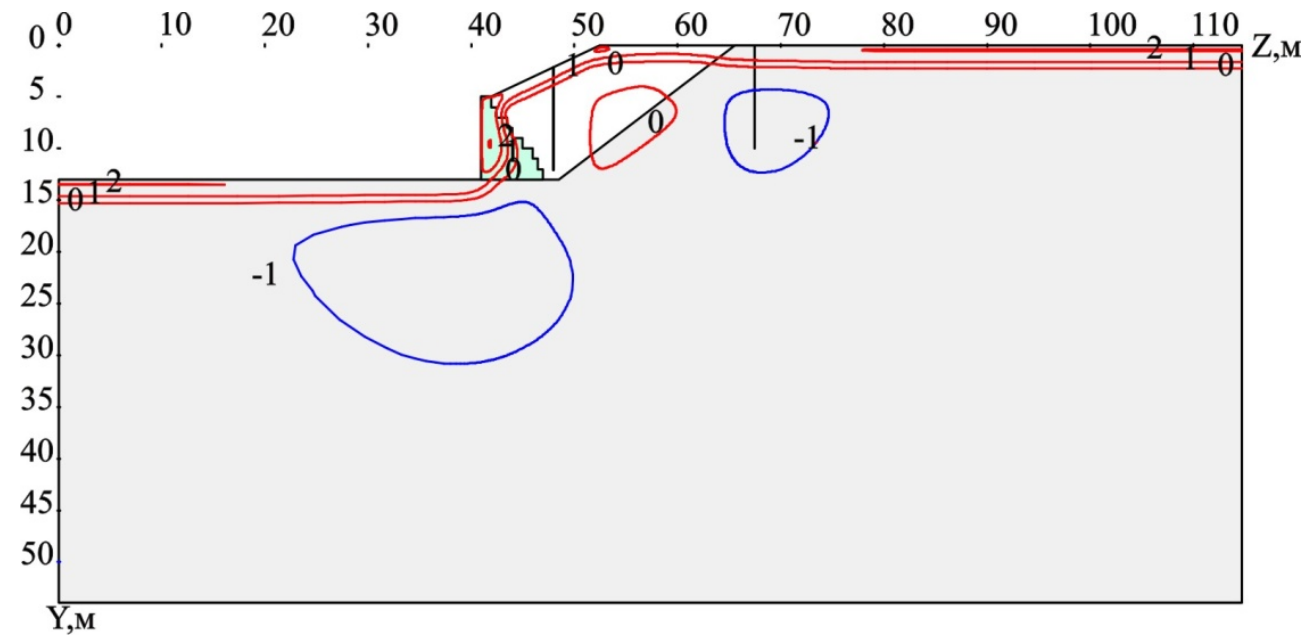

Fig.3. Temperature $\left({ }^{\circ} \mathrm{C}\right)$ distribution in the ground with thermal stabilizers (mid-September, year 1 of the thermal stabilizers operation) 


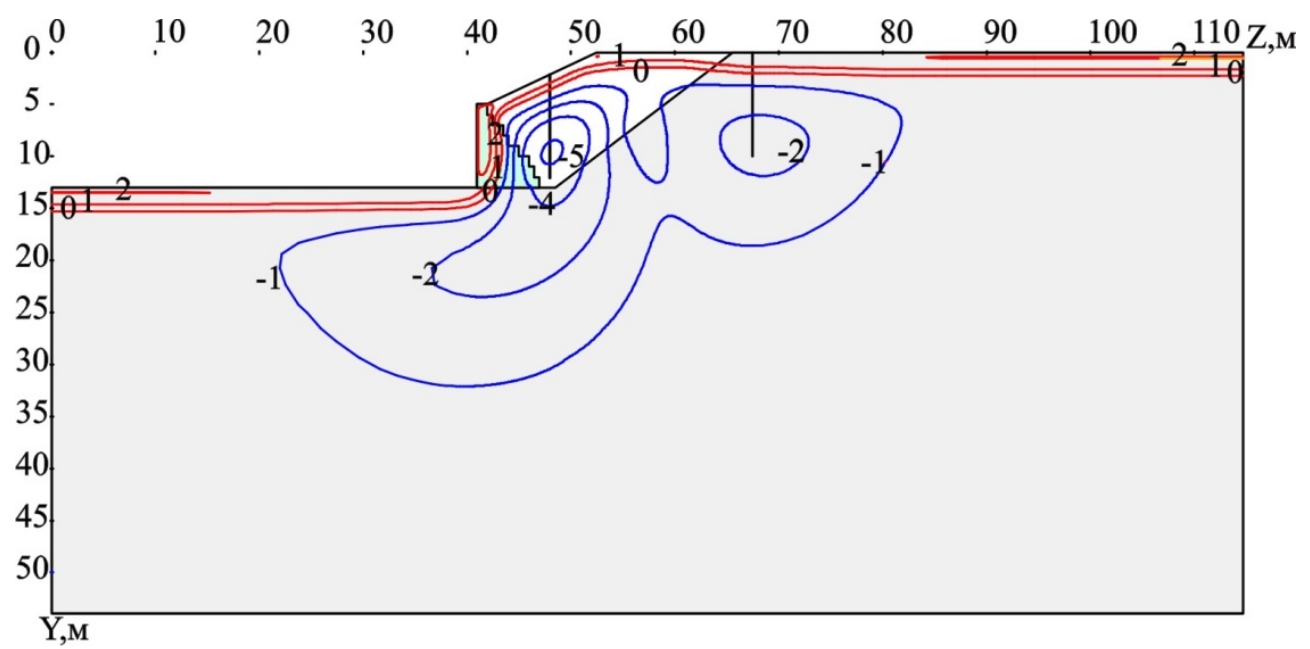

Fig.4. Temperature $\left({ }^{\circ} \mathrm{C}\right)$ distribution in the ground with thermal stabilizers (mid-September, year 4 of the thermal stabilizers operation)

\section{Temperature regime forecast for the fill slope after thermal stabilization}

After four years of the thermal stabilizers operation, a stable negative temperature is established inside the fill slope, after which they can be turned off. The calculations showed that in the following years, after the thermal stabilizers are turned off, the frozen zone in the fill slope is maintained, and the slope gradually switches to the natural seasonal temperature regime (see Figure 5).

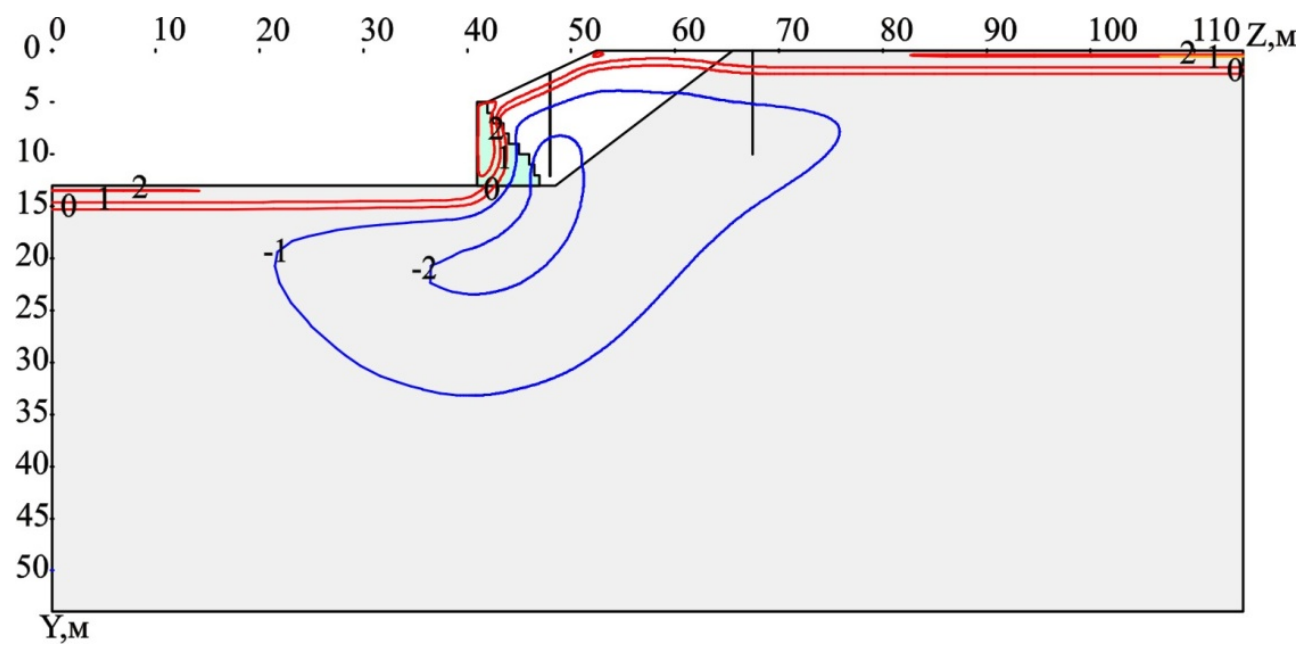

Fig.5. Temperature $\left({ }^{\circ} \mathrm{C}\right)$ distribution in the ground in year 2 after turning the thermal stabilizers off (mid-September)

\section{Conclusions}

1. After the construction of a fill slope in the warm season, an extensive thawed zone forms in it. In the first four years, in summer, the talik merges with the seasonally thawed soil, 
which, if the hydrogological regime of surface waters is disturbed, can result in the formation of zones with high water content. In subsequent years, the talik stops merging with the seasonally thawed soil, but continues to be a source of instability and deformation of the slope. According to our calculations, the thawed zone inside the embankment disappears completely in the eleventh year.

2. The calculations showed the effectiveness of using seasonal thermal stabilizers to increase the stability of a fill slope by freezing. The thawed zone in a fill slope gradually decreases and after four years of the heat stabilizers operation, it completely disappears.

3. After the thermal stabilization is complete, in subsequent years, the frozen zone in the fill slope remains, and the slope gradually switches to the natural seasonal temperature regime.

\section{References}

1. E. K. Romanova, Y. A. Khokholov, A. S. Kurilko, Thermal physics and power industry in Arctic and sub-Arctic regions: Proceedings of the All-Russian Conference (Melnikov Permafrost Institute, Yakutsk, 2019)

2. A. A. Samarskii, B. D. Moiseenko, COMP MATH MATH PHYS+, 5, 816-827 (1965)

3. A. N. Tikhonov, A. A. Samarskii, Mathematical Physics Equations (Nauka, Moscow, 1977) 